\title{
ENZIMAS DIGESTIVAS DE JUVENIS DE CARPA CAPIM ALIMENTADOS COM FORRAGEM E RAÇÃO
}

\author{
DIGESTIVE ENZYMES IN GRASS CARP JUVENILES FED WITH \\ FORAGE AND RATION
}

\begin{abstract}
Costa, M.L. ${ }^{1}$, Radünz Neto, J. ${ }^{1 *}$, Lazzari, R. ${ }^{1}$, Veiverberg, C.A. ${ }^{1}$, Sutili, F.J. ${ }^{1}$ e Loro, V.L. ${ }^{2}$
${ }^{1}$ Laboratório de Piscicultura. Departamento de Zootecnia. Universidade Federal de Santa Maria. Rio Grande do Sul. Brasil. *jradunzneto@yahoo.com.br

${ }^{2}$ Departamento de Química. Universidade Federal de Santa Maria. Rio Grande do Sul. Brasil.
\end{abstract}

\section{PaLAVRAS ChaVE ADICIONAIS}

Suplementação. Amilase. Proteases. Digestão. Capim teosinto.

\section{RESUMO}

Objetivou-se avaliar a atividade de enzimas digestivas de 240 juvenis $(20,15 \pm 0,23 \mathrm{~g})$ de carpa capim (Ctenopharyngodon idella) alimentadas com capim teosinto e ração durante 45 dias e criados em sistema de recirculação de água, composto por 12 tanques (20 peixes/tanque). Os tratamentos foram: $\mathrm{C}=$ somente capim teosinto; $\mathrm{SD}=$ capim teosinto+ração diariamente (3\% PV); SA= capim teosinto+ração a cada dois dias (3\% PV); $R=$ somente ração $(3 \% \mathrm{PV})$. Após o período de alimentação, 6 peixes por tratamento foram abatidos para análise (na porção anterior e posterior do trato) das enzimas digestivas amilase, maltase, tripsina e quimiotripsina. Também foram avaliados os pesos do fígado, do trato digestório, comprimento do trato e ganho em peso relativo. A associação de capim e ração, diariamente, resulta em maior peso do fígado, ganho em peso relativo e menor atividade de maltase. A atividade de amilase, o peso e comprimento do trato digestório não variaram $(p>0,05)$. A atividade das proteases alcalinas é menor quando juvenis de carpa capim são alimentadas exclusivamente com ração.

\section{SUMMARY}

The activity of digestive enzymes of grass carp (Ctenopharyngodon idella) juveniles fed with teosinte grass and ration during 45 days

\section{AdDITIONAL KEYWORDS}

Digestion. Suplementation. Amylase. Proteases. Teosinte grass.

was evaluated in 240 juveniles $(20.15 \pm 0.23 \mathrm{~g})$, reared in 12 water recirculating tanks (20 fish/ tank). The treatments were: $\mathrm{C}=$ only teosinte grass; $\mathrm{SD}=$ teosinte grass+daily supplementation (3\% BW); SA= teosinte grass+supplementation every two days ( $3 \% \mathrm{BW}) ; \mathrm{R}=$ only ration $(3 \% \mathrm{BW})$. After the feeding period, 6 fish per treatment were killed for analysis (in anterior and posterior intestine) of digestive enzymes: amylase, maltase, trypsin and chymotripsin. The weights of liver and digestive tract, tract length and relative weight gain also were evaluated. The association of grass and ration, daily, results in higher liver weight and relative weight gain and lower maltase activity. It was not observed effect $(p>0.05)$ in amylase activity, weight and length of tract. Alkaline proteases activities are lower when grass carp juveniles fed only ration.

\section{INTRODUÇÃO}

A distribuição das enzimas no intestino dos pixes varia com o hábito alimentar e a morfologia tecidual (Tengjaroenkul et al., 2000). O conhecimento de cada enzima presente no trato e a caracterização e quantificação da atividade enzimática podem contribuir para a elaboração de programas alimentares eficientes e busca de 
ingredientes alternativos nas dietas.

A carpa capim (Ctenopharyngodon idella), de hábito alimentar herbívoro, consome grande variedade de plantas terrestres e aquáticas, em grande quantidade (até $60 \%$ do peso vivo por dia). Entretanto, na fase de recria, necessita da associação de forragem e ração balanceada para obter crescimento mais rápido (Camargo et al., 2006). Estes autores observaram que o capim teosinto (Euchlaena mexicana) é a forragem de maior aceitabilidade pelas carpas capim, além de resultar em maior ganho em peso e melhor fator de condição (Camargo et al., 2006).

Pouco se conhece a respeito da atividade de enzimas digestivas da carpa capim quando recebe alimentação associada de forragem e ração. A atividade enzimática normalmente está relacionada com o hábito alimentar da espécie. Por exemplo, peixes herbívoros geralmente apresentam alta atividade amilolítica (Sabapathy e Teo, 1992), entretanto, espécies também podem apresentar alta atividade de enzimas proteolíticas, como tripsina e quimiotripsina (Kuz'mina e Kuz'mina, 1990; Ckakrabarti et al., 1995). A carpa capim apresenta alta atividade de proteases alcalinas no intestino, sendo a tripsina a mais importante (Liu et al., 2008).

Em face das poucas informações sobre a digestão de alimentos por esta espécie, o objetivo deste trabalho foi estudar a atividade de enzimas digestivas de juvenis de carpa capim alimentados com capim teosinto (Euchlaena mexicana), e associação de ração e capim.

\section{MATERIALE MÉTODOS}

A criação dos peixes foi realizada no Laboratório de Piscicultura da Universidade Federal de Santa Maria-RS (altitude $95 \mathrm{~m}$, latitude $29^{\circ} 43^{\prime}$ 'S e longitude $53^{\circ} 42^{\prime} \mathrm{W}$ ). Os peixes foram alimentados durante 45 dias, entre os meses de fevereiro e abril de 2005.

No experimento, 240 juvenis de carpa capim foram distribuídos em 12 tanques
(8501) em sistema de recirculação de água com temperatura controlada. Os peixes foram colocados nas instalações experimentais 10 dias antes do início do experimento para adaptação ao sistema de criação e aos alimentos. Durante este período, foram alimentados com capim teosinto à vontade.

Os tratamentos avaliados foram: $\mathrm{C}=$ somente capim teosinto; $\mathrm{SD}=$ capim teosinto+ suplementação diária com ração(3\% PV); SA= capim teosinto+suplementação a cada dois dias com ração (3\% PV); R= somente ração diariamente(3\% PV).

O capim teosinto foi escolhido como forragem baseando-se nos resultados de Camargo et al. (2006). A dieta experimental (tabela I) foi preparada através da mistura dos ingredientes secos com água e posterior peletização em máquina de moer carne. Após, a ração foi levada à estufa com circulação forçada de ar por 48 horas $\left(40^{\circ} \mathrm{C}\right)$, sendo mantidas em refrigeração $\left(-4^{\circ} \mathrm{C}\right)$ até 0 momento de fornecimento aos animais.

A alimentação foi oferecida duas vezes ao dia, sendo a ração às 9 horas e o capim às 17 horas. A quantidade inicial de teosinto fornecida foi de $15 \%$ do peso vivo (PV), de acordo com Camargo et al. (2006). Antes de cada alimentação da manhã, os restos de capim foram coletados e pesados. A partir destes dados realizou-se ajuste da oferta diária de forragem, aumentando-se a oferta em $5 \%$ da biomassa quando o consumo diário fosse total. Após a coleta das sobras de capim, era feita a limpeza das unidades experimentais por sifonagem.

Ao final do período de alimentação, seis peixes por tratamento foram mantidos em jejum (24 horas) e posteriormente sedados com trifenóxi-etanol $(0,03 \%)$ para o abate. Os peixes foram sacrificados através de punção cervical, após foram retirados o fígado e o trato digestório e obtidas as medidas de peso do fígado, peso e comprimento do trato digestório. Após a pesagem e medição o trato digestório foi imediatamente removido e estocado a $-20^{\circ} \mathrm{C}$ dividido em duas porções: anterior e poste-

Archivos de zootecnia vol. 60, núm. 231, p. 564. 
Tabela I. Composição (\%) da dieta experimental utilizada no experimento. (Composition (\%) of experimental diet used in the feeding trial).

\begin{tabular}{lcc}
\hline Ingredientes & Ração & Capim \\
\hline Teosinto & - & 100 \\
Farinha de carne e ossos & 12 & - \\
Farelo de soja & 35 & - \\
Farelo de trigo & 25 & - \\
Milho & 20 & - \\
Fosfato bicálcico & 1 & - \\
Óleo de soja & 5 & - \\
Sal comum & 1 & - \\
Vitaminas e minerais & 1 & - \\
\hline
\end{tabular}

Composição centesimal analisada (\%)

$\begin{array}{lcc}\text { Umidade } & 7,73 & - \\ \text { Proteína bruta }^{1} & 30,52 & 12,60 \\ \text { Fibra bruta }^{1} & 2,67 & 27,14 \\ \text { Extrato etéreo }^{1} & 9,84 & 6,61 \\ \text { Matéria mineral }^{1} & 12,38 & 6,72 \\ \text { Extrativos não-nitrogenados }^{1} & 44,59 & 43,74\end{array}$

${ }^{1}$ Composição expressa com base na matéria seca. Análises realizadas no Laboratório de Nutrição Animal/Departamento de Zootecnia/UFSM.

rior. Posteriormente os tecidos foram homogeneizados em tampão (10 mM fosfato/ 20 mM tris-pH 7,0) durante 10 minutos $\left(4^{\circ} \mathrm{C}\right)$, utilizando um homogenizador (PotterElvehijen). Os sobrenadantes obtidos foram utilizados nos ensaios enzimáticos. As enzimas analisadas (maltase, amilase, tripsina e quimiotripsina) foram determinadas nas duas porções do trato (anterior e posterior). Também foi calculado o ganho em peso relativo (\%) dos peixes, segundo a fórmula:

$$
\begin{aligned}
& \text { GPR }=\{(\text { peso final }(g)-\text { peso inicial }(\mathrm{g})) / \text { peso } \\
& \text { inicial }\} \times 100
\end{aligned}
$$

A atividade de tripsina foi realizada com $\alpha$ - $\rho$-toluenesulphonyl- L-arginine methyl ester hydrochloride (TAME). Os extratos foram incubados por 2 minutos em $2 \mathrm{ml}$ de tampão Tris/CaCl , empH 8,1. A quimiotripsina foi determinada com benzoyl tyrosine ethyl ester (BTEE). A incubação dos extratos foi realizada por dois minutos com tampão tris/ $\mathrm{CaCl}_{2}$ ( $2 \mathrm{ml}$ ), em pH 7,8. Para estas duas enzimas as análises foram realizadas em duplicata de cada peixe coletado, sendo as leituras realizadas em espectrofotômetro (247 e 256 nm, respectivamente), seguindo o protocolo descrito por Hummel (1959). Uma unidade de enzima foi definida como a quantidade de enzima necessária para hidrolisar $1 \mu$ g de substrato (TAME ou BTEE) por min/mg proteína.

A atividade de amilase foi determinada em tampão fosfato-citrato $(0,2 \mathrm{M}, \mathrm{pH} 7,0$, $\mathrm{NaCl} 0,5 \%$ ) com concentração de amido de $2,5 \%$. A reação foi interrompida com a adição de $\mathrm{Ba}(\mathrm{OH})_{2}\left(0,3 \mathrm{~N}\right.$ and $\left.\mathrm{ZnSO}_{4} 5 \%\right)$. O protocolo experimental foi modificado de acordo com Bernfeld (1955). A determinação da hidrólise do amido foi segundo metodologia de Park-Johnson (1949). A leitura foi realizada em $660 \mathrm{~nm}$. Uma unidade desta enzima foi definida como $1 \mu \mathrm{mol}$ de glicose liberada do amido por min/mg de proteína.

A maltase foi determinada também em tampão fosfatocitrato, com 5\% de concentração de maltose e $20 \mu \mathrm{l}$ de extrato bruto. Estes foram incubados durante 60 minutos $\left(25^{\circ} \mathrm{C}\right)$. A leitura foi interrompida com PCA 0,6 N $(0,1 \mathrm{ml})$ e adicionado $0,1 \mathrm{ml}$ de $\mathrm{KHCO}_{3}$. As amostras foram centrifugadas a 3000 g por 5 minutos e a glicose determinada a $500 \mathrm{~nm}$, com glicose oxidase (Kit-Labtest).

Todas as atividades enzimáticas foram expressas em unidade/mg de proteína tecidual. A proteína dos extratos brutos foi determinada pelo método de Lowry et al. (1951), utilizando albumina de soro bovino como padrão.

O delineamento experimental utilizado foi o inteiramente casualizado (DIC), com quatro tratamentos e seis repetições. Os dados foram submetidos à análise de variância e teste de Tukey $(\mathrm{p}<0,05)$. Os valores de quimiotripsina foram submetidos à transformação logarítmica de base 10 para 
Tabela II. Atividade de maltase e amilase (U/mg proteína) em juvenis de carpa capim. (Amylase e maltase activity (U/mg protein) in grass carp juveniles).

\begin{tabular}{lcccc}
\hline Enzima & C & $\begin{array}{c}\text { Tratamentos } \\
\text { SD }\end{array}$ & SA \\
\hline Amilase & & & & \\
$\quad$ Porção anterior & $0,015 \pm 0,002^{\mathrm{a}}$ & $0,009 \pm 0,001^{\mathrm{b}}$ & $0,013 \pm 0,001^{\mathrm{ab}}$ & $0,012 \pm 0,001^{\mathrm{ab}}$ \\
$\quad$ Porção posterior & $0,015 \pm 0,001^{\mathrm{a}}$ & $0,015 \pm 0,001^{\mathrm{a}}$ & $0,014 \pm 0,001^{\mathrm{a}}$ & $0,013 \pm 0,001^{\mathrm{a}}$ \\
Maltase & & & & \\
$\quad$ Porção anterior & $0,477 \pm 0,06^{\mathrm{c}}$ & $0,490 \pm 0,07^{\mathrm{bc}}$ & $0,761 \pm 0,05^{\mathrm{b}}$ & $1,310 \pm 0,09^{\mathrm{a}}$ \\
$\quad$ Porção posterior & $2,150 \pm 0,21^{\mathrm{a}}$ & $1,102 \pm 0,31^{\mathrm{b}}$ & $1,916 \pm 0,20^{\mathrm{ab}}$ & $1,327 \pm 0,16^{\mathrm{ab}}$ \\
\hline
\end{tabular}

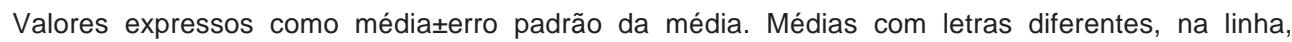
apresentam diferença significativa pelo teste de Tukey $(p<0,05) . C=$ capim teosinto; $S D=$ capim teosinto+suplementação diária (3\% PV); SA= capim teosinto+suplementação a cada dois dias (3\%PV); $\mathrm{R}=$ ração $(3 \% \mathrm{PV})$.

normalização. Foram realizados estudos de correlação de Pearson (r) entre as enzimas avaliadas, os quais foram considerados significativos quando o valor de $\mathrm{P}$ foi igual ou inferior a 0,05. Para as análises foi utilizado o pacote estatístico SAS (1997).

\section{RESULTADOSEDISCUSSÃO}

A qualidade da água do sistema de criação (temperatura $25,1 \pm 2,2^{\circ} \mathrm{C}$; $\mathrm{pH} 6,8 \pm 0,5$;

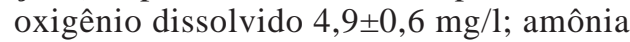
total 0,4 $\pm 0,1 \mathrm{mg} / \mathrm{l}$; nitrito $0,01 \pm 0,005 \mathrm{mg} / \mathrm{l}$; alcalinidade total $45,2 \pm 11,3 \mathrm{mg} / \mathrm{l}$ ) foi monitorada diariamente e esteve dentro das condições adequadas para o crescimento da espécie (Poli e Arana, 2004).

Em relação à atividade de amilase (tabela II), não se observou diferenças na porção posterior do trato, entretanto, na porção anterior os peixes alimentados somente com capim (C) apresentaram maiores valores em relação aos suplementados diariamente com ração (SD). Independente das diferenças entre tratamentos verificou-se que a carpa capim apresenta alta atividade desta enzima, demonstrando a capacidade de aproveitamento do amido. Alguns autores têm relatado que existe correlação positiva entre peixes de hábito alimentar herbívoro e altas atividades da enzima amilase (Hidalgo et al., 1999).

A atividade de amilase também é muito variável entre as espécies. Muitas vezes, peixes de hábito alimentar carnívoro podem ter maior atividade desta enzima, o que sugere certa adaptação do complexo enzimático (Sabapathy e Teo, 1992; Seixas Filho et al., 1999). Para o tambaqui (Colossoma macropomum), o aumento do lipídio e a diminuição da proteína dietária são inversamente proporcionais à atividade de amilase (Almeida et al., 2006).

Para a carpa capim, os fatores que alteram a atividade enzimática ainda não estão bem esclarecidos. Ensaios de digestibilidade podem auxiliar na compreensão da digestão da carpa capim, pois neste estudo a atividade de amilase no tratamento a base de capim (C) foi similar ao somente ração (R). Isto demonstra que a quantidade desta enzima não significa melhor aproveitamento, pois Camargo et al. (2006) observaram que o desempenho em peso de juvenis de carpa capim alimentadas com ração é muito superior ao dos peixes alimentados exclusivamente com capim.

A atividade de maltase na porção anterior do trato dos juvenis de carpa capim

Archivos de zootecnia vol. 60, núm. 231, p. 566. 
Tabela III. Coeficientes de correlação de Pearson entre as enzimas avaliadas no estudo. (Pearson correlation coefficients among the enzymes evaluated in the study.)

\begin{tabular}{|c|c|c|c|c|c|c|c|}
\hline & M P & AA & AP & TA & TP & QA & QP \\
\hline MA & $\begin{array}{c}-0,12 \\
(0,53)\end{array}$ & $\begin{array}{c}0,04 \\
(0,81)\end{array}$ & $\begin{array}{l}-0,35 \\
(0,06)\end{array}$ & $\begin{array}{c}-0,72 \\
(0,0001)\end{array}$ & $\begin{array}{c}-0,71 \\
(0,0001)\end{array}$ & $\begin{array}{c}-0,81 \\
(0,0001)\end{array}$ & $\begin{array}{c}-0,82 \\
(0,0001)\end{array}$ \\
\hline MP & & $\begin{array}{c}0,30 \\
(0,11)\end{array}$ & $\begin{array}{c}0,14 \\
(0,45)\end{array}$ & $\begin{array}{c}0,28 \\
(0,14)\end{array}$ & $\begin{array}{c}0,45 \\
(0,01)\end{array}$ & $\begin{array}{c}0,23 \\
(0,24)\end{array}$ & $\begin{array}{c}0,16 \\
(0,40)\end{array}$ \\
\hline$A A$ & & & $\begin{array}{c}0,06 \\
(0,74)\end{array}$ & $\begin{array}{c}0,14 \\
(0,47)\end{array}$ & $\begin{array}{c}0,21 \\
(0,27)\end{array}$ & $\begin{array}{l}-0,07 \\
(0,72)\end{array}$ & $\begin{array}{l}-0,10 \\
(0,60)\end{array}$ \\
\hline $\mathrm{AP}$ & & & & $\begin{array}{c}0,33 \\
(0,09)\end{array}$ & $\begin{array}{c}0,36 \\
(0,06)\end{array}$ & $\begin{array}{c}0,38 \\
(0,04)\end{array}$ & $\begin{array}{c}0,37 \\
(0,05)\end{array}$ \\
\hline TA & & & & & $\begin{array}{c}0,71 \\
(0,0001)\end{array}$ & $\begin{array}{c}0,57 \\
(0,002)\end{array}$ & $\begin{array}{c}0,48 \\
(0,01)\end{array}$ \\
\hline TP & & & & & & $\begin{array}{c}0,80 \\
(0,0001)\end{array}$ & $\begin{array}{c}0,72 \\
(0,0001)\end{array}$ \\
\hline QA & & & & & & & $\begin{array}{c}0,98 \\
(0,0001)\end{array}$ \\
\hline
\end{tabular}

Valores entre parênteses indicam a significância da correlação (valor de p).

MA: maltase/porção anterior; MP: maltase/porção posterior; AA: amilase/porção anterior; AP: amilase/ porção posterior; TA: tripsina/porção anterior; TP: tripsina/porção posterior; QA: quimiotripsina/porção anterior; QP: quimiotripsina/porção posterior.

alimentados somente com ração (R) foi maior que nos demais tratamentos. Entretanto, na porção posterior não ocorreu diferença de atividade entre os peixes do tratamento $\mathrm{R}$ (somente ração), SA (suplementação alternada) e C (somente capim). Não foi observada correlação significativa $(p<0,05)$ entre amilase e maltase (tabela III). Entretanto, verificou-se alta correlação negativa da atividade de maltase na porção anterior do trato com as proteases alcalinas estudadas (70\% com tripsina e $80 \%$ com quimiotripsina). Esta correlação negativa pode estar associada à composição da dieta utilizada no experimento. A utilização dos carboidratos pela carpa capim é afetada pela complexidade destes compostos, resultando em alterações enzimáticas e de peso visceral (Tian et al., 2004). Estes autores avaliaram o aproveitamento de glicose e amido de milho para a carpa capim e verificaram que a inclusão de $30 \%$ de glicose na dieta proporciona menor deposição lipídica na carcaça e gordura visceral.
Em relação ao peso e comprimento do trato digestório (figura 1a e 1c), não se verificou diferenças entre os tratamentos. Um dos motivos desse resultado pode estar relacionado ao curto período de alimentação (45 dias), pois geralmente a alimentação somente com ingredientes fibrosos aumenta o comprimento do trato da carpa capim (Stroband, 1977).

O peso do fígado (figura $1 \mathbf{b}$ ) foi maior no tratamento com suplementação diária de ração (SD), enquanto que os peixes alimentados somente com capim tiveram menor valor. Isto pode estar relacionado aomaior consumo de matéria seca e lipídios no tratamento SD. Deve-se levar em consideração que o aumento do peso do fígado não indica necessariamente melhor aproveitamento dos alimentos, mas sim, uma resposta à composição da dieta. Juvenis de carpa capim (peso inicial de 6,5 g) apresentaram aumento linear do peso do fígado de acordo com a elevação da quantidade de lipídio da dieta (Du et al., 2005). 

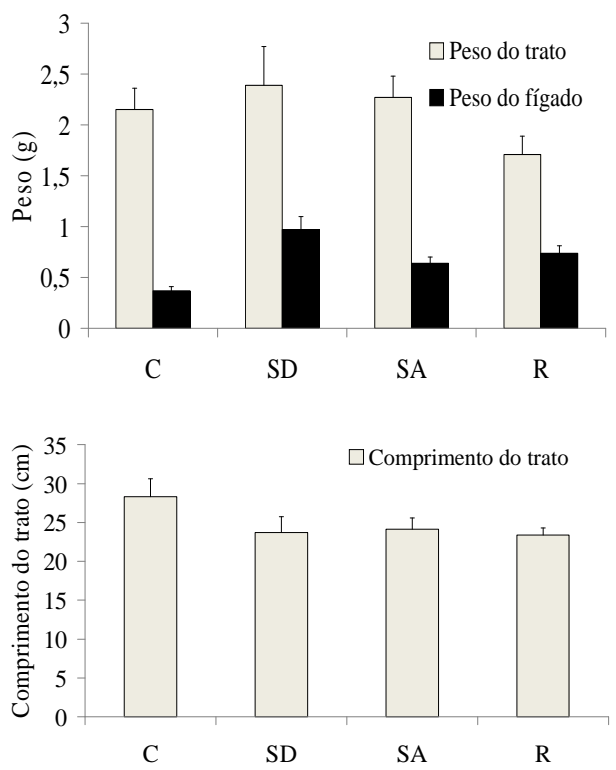

Tratamentos: $\mathrm{C}=$ capim teosinto; $\mathrm{SD}=$ capim teosinto+suplementação diária (3\% PV); SA= capim teosinto+suplementação a cada dois dias (3\% PV); R= ração (3\% PV).

Figura 1. Pesos de fígado e trato e comprimento do trato digestório de juvenis de carpa capim alimentados com teosinto e ração. (Tract and liver weight and length of digestive tract of grass carp juveniles fed with teosinto grass and ration).

A atividade de tripsina (figura 2a) foi maior nos peixes alimentados exclusivamente com capim, enquanto que as carpas alimentadas somente com ração tiveram a menor atividade. Quanto a quimiotripsina (figura 2b), os peixes alimentados somente com ração tiveram a menor atividade, nas duas porções do trato.

A atividade das proteases pode estar relacionada com a quantidade de alimento ingerido, como observado para a tainha (Mugil platanus)(Galvão et al., 1997). Além disso, as carpas possuem alto potencial de secreção de proteases (Hidalgo et al., 1999), principalmente para digerir as proteínas dos ingredientes de origem vegetal, que
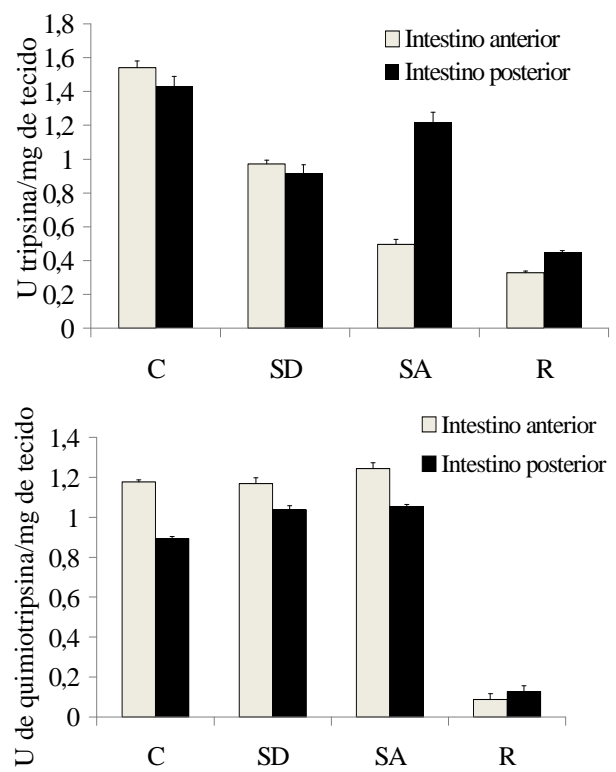

Tratamentos: $\mathrm{C}=$ capim teosinto; $\mathrm{SD}=$ capim teosinto+suplementação diária (3\%PV); SA= capim teosinto+suplementação a cada dois dias (3\%PV); R= ração (3\% PV).

Figura 2. Atividade de tripsina e quimiotripsina em juvenis de carpa capim alimentadas com capim teosinto e ração. (Trypsin and chymotripsin activity in grass carp juveniles fed with teosinte grass and ration).

possuem menor digestibilidade (Kuz'mina, 1990). Para a carpa capim, existe correlação entre a quantidade de alimento e a secreção de enzimas digestivas (Das e Tripathi, 1991). Esperava-se que a atividade de tripsina seria maior no tratamento de suplementação diária (SD), entretanto, a alta atividade desta enzima nos peixes alimentados somente com capim teosinto pode ser uma forma de o peixe compensar a baixa qualidade e quantidade de proteína na dieta consumida.

Observou-se alta correlação entre a atividade de tripsina da porção posterior do intestino com a quimiotripsina (72 e 80\%) (tabela III). Trabalhos conduzidos com o jundiá (Rhamdia quelen) e com o pintado 


\section{FEITO DA DIETA SOBRE AS ENZIMAS DIGESTIVAS DE CARPA CAPIM}



Figura 3. Ganho em peso relativo (\%) de juvenis de carpa capim alimentadas com capim teosinto e ração. (Relative weight gain (\%) in grass carp juveniles fed with teosinte grass and ration).

(Pseudoplatystoma corruscans) demonstram que a atividade das proteases alcalinas (tripsina e quimotripsina) pode sofrer maior influência do tipo de dieta do que pela variação da quantidade de proteína (Lundstedt et al., 2004; Melo et al., 2006). Peixes onívoros como o pacu (Piaractus mesopotamicus) estão mais sujeitos a fatores inibitórios da dieta do que peixes carnívoros em relação à atividade de proteases alcalinas (Pérez et al., 2003).

O crescimento dos juvenis de carpa capim foi maior no tratamento com suplementação diária de ração (SD) (figura 3). Os peixes que foram alimentados somente com capim teosinto ou somente com ração obtiveram os piores desempenhos. Isto mostra que a associação de forragem com ração é

\section{BIBLIOGRAFIA}

Almeida, L.C., Lundstedt, L.M. and Moraes, G. 2006. Digestive enzyme response of tambaqui (Colossoma macropomum) fed on different levels of protein and lipid. Aquac. Nutr., 12: 443450.

Bernfeld, P. 1955. Enzymes of carbohydrate metabolism. In: S.P. Colowick and N.P. Kaplan (Eds.). Methods in enzymology. Academic Press. New York. 149 pp. necessária para o bom desenvolvimento desta espécie.

Percebe-se que os peixes alimentados somente com ração apresentaram menor atividade de proteases alcalinas, demonstrando que o capim teosinto exerce influência na atividade de proteases. Pela maior porção fibrosa, o capim pode aumentar o peristaltismo intestinal, resultando em maior estímulo a secreção enzimática. Segundo Das e Tripathi (1991), a alta atividade de protease observada na carpa capim sugere a inclusão de fontes de origem animal nas dietas. Devese ressaltar também que a carpa capim possui bactérias produtoras de celulase em seu trato digestório, o que auxilia na digestão de componentes fibrosos como os capins (Saha et al., 2006). Mais estudos deverão ser realizados, associando, além das enzimas digestivas, parâmetros de metabolismo intermediário, de forma a entender melhor como este peixe aproveita os diferentes alimentos.

\section{CONCLUSÕES}

A associação de capim e ração, fornecida diariamente, proporciona maior peso do fígado, menor atividade de maltase e melhor desenvolvimento em juvenis de carpa capim. A atividade de amilase, o peso e comprimento do trato digestório não variam de acordo com o manejo alimentar adotado entre ração e/ou capim teosinto. A atividade das proteases alcalinas é menor quando juvenis de carpa capim são alimentados exclusivamente com ração.

Camargo, J.B., Radünz Neto, J., Emanuelli, T., Lazzari, R., Costa, M.L., Losekann, M.E., Lima, R.L., Scherer, R., Augusti, P.R., Pedron, F.A. e Medeiros, T.S. 2006. Cultivo de alevinos de carpa capim (Ctenopharyngodon idella) alimentados com ração e forragens cultivadas. Rev. Bras. Agro., 12: 211-215.

Chakrabarti, I., Gani, M.D.A., Chaki, K.K., Sur, R. and Misra, K.K. 1995. Digestive enzymes in 11 
freshwater teleost fish species in relation to food habit and niche segregation. Comp. Biochem. Physiol. A., 112: 167-177.

Das, K.M. and Tripathi, S.D. 1991. Studies of digestive enzymes of grass carp (Ctenopharyngodon idella Val.). Aquaculture, 92: 21-32.

Du, Z.Y., Liu, Y.J. and Tian, L.X. 2005. Effect of dietary lipid level on growth, feed utilization and body composition by juvenile grass carp (Ctenopharyngodon idella). Aquac. Nutr.,11: 139-146.

Galvão, M.S.N., Yamanaka, N., Fenerich-Verani, N. e Pimentel, C.M.M. 1997. Estudos preliminares sobre enzimas proteolíticas da tainha Mugil platanus Günther, 1880 (Osteichthyes, Mugilidae) durante as fases larval e juvenil. $B$. Inst. Pesca, 24: 101-110.

Hidalgo, M.C., Urea, E. and Sanz, A. 1999. Comparative study of digestive enzymes in fish with different nutritional habits. Proteolytic and amylase activities. Aquaculture, 170: 267-283.

Hummel, B.C.W. 1959. A modified spectrophotometric determination of chymotrypsin, trypsin and trombin. Can. J. Biochem Physiol., 37: 1393-1399.

Kuz'mina, V.V. and Kuz'mina, Y.G. 1990. Level of total proteolytic activity in some species of fish from the Volga barin. J. Ichthyol., 31: 25-35.

Liu, Z.Y., Wang, Z., Xu, S.Y. and Xu, L.N. 2008. Partial characterization and activity distribution of proteases along the intestine of grass carp, Ctenopharyngodon idella (Val.). Aquacult. Nutr., 14: 31-39.

Lowry, O.H., Rosebrough, N.J., Farr, A.L. and Randall, R.J. 1951. Protein measurement with the folin-phenol reagent. J. Biol. Chem., 193: 265-275.

Lundstedt, L.M., Melo, J.F.B. and Moraes, G. 2004. Digestive enzymes and metabolic profile of Pseudoplatystoma corruscans (Teleostei, Siluriformes) in response to diet composition. Comp. Biochem. Physiol. B., 137: 331-339.

Melo, J.F.B., Lundstedt, L.M., Metón, I., Baanante, I.V. and Moraes, G. 2006. Effects of dietary levels of protein on nitrogenous metabolism of Rhamdia quelen. Comp. Biochem. Physiol. A., 145: 181-187.

Mukhopadhyay, P.K. and Kaushik, S.J. 2001. Nutritional requirements of the Indian major carps. Intern. Aqua Feed Direct. Buyers' Guide. 1: 28-32.

Park, J.T. and Johnson, M.J. 1949. A submicro determination of glucose. J. Biol. Chem., 181: 149-151.

Poli, C.R. e L.V. Arana. 2004. Qualidade da água em aqüicultura. In: Poli, C.R. A.T.B. Poli E.R. Andratta e Beltrame, E. (Orgs.). Editora Multitarefa. Aquicultura: experiências brasileiras. Florianópolis. SC. pp. 45-72.

Pérez, J.J., Wicki, G.A., Moyano, F.J. e Alarcón, F.J. 2003. Evaluación del efecto de inibidores de proteasa presentes em ingredientes vegetales utilizables en piensos para dos especies piscícolas cultivadas em Argentina: pacu (Piaractus mesopotamicus) y pejerrey (Odontesthes bonariensis). In: II Congresso Iberoamericano Virtual de Acuicultura. Zaragoza. España. Anais... pp. 442-454.

Sabapathy, U. and Teo, L.H. 1992. A quantitative study of some digestive enzymes in the rabbitfish, Siganus canaliculatus and the sea bass, Lates calcarifer. J. Fish Biol., 42: 595602.

Saha, S., Roy, R.N., Sen, S.K. and Ray, A.K. 2006. Characterization of cellulase-producing bacteria from the digestive tract of tilapia, Oreochromis mossambica (Peters) and grass carp, Ctenopharyngodon idella (Valenciennes). Aquac. Res., 37: 380-388.

SAS. 1997. Statistical analysis system. User's Guide. $4^{\mathrm{a}} \mathrm{ed}$. North Caroline. $846 \mathrm{pp}$.

Seixas Filho, J.T., Oliveira, M.G.A., Donzele, J.L. e Gomide, A.T.M. 1999. Avaliação da atividade de amilase em quimo de três espécies tropicais de peixe Teleostei de água doce. Rev. Bras. Zootecn., 28: 907-913.

Stroband, H.W.J. 1977. Growth and diet dependant structural adaptations of the digestive tract in juvenile grass carp (Ctenopharyngodon idella Val.). J. Fish Biol., 11: 167-174.

Tengjaroenkul, B., Smith, B.J., Caceci, T. and Smith, S.A. 2000. Distribution of intestinal enzyme activities along the intestinal tract of cultured nile tilapia, Oreochromis niloticus L. Aquaculture, 182: 317-327.

Tian, L.X., Liu, Y.J. and Hung, S.S. 2004. Utilization of glucose and cornstarch by juvenile grass carp. N. Am. J. Aquaculture, 66: 141-145.

Archivos de zootecnia vol. 60, núm. 231, p. 570. 